\title{
Development of Bittergourd Fermented Beverage Using Response Surface Methodology
}

\author{
C.S. Devaki and K.S. Premavalli* \\ Food Preservation Discipline, Defence Food Research Laboratory, Siddarthanagar, Mysore - 570011 , \\ Karnataka, India
}

\begin{abstract}
Bittergourd (Momordica charantia) is used as a vegetable by the Asian community and is commonly used as an antidiabetic and antihyperglycemic agent. The aim of the present study was to develop nutritionally strengthful, highly acceptable, shelf stable bittergourd beverage by fermented process using statistical software on Response Surface Methodology (RSM). The optimization of the fermentation process with reference to curd concentration and the period has been attempted by using RSM with more emphasis on nutritional and functional considerations. The statistical design gave 13 formulations, where the fermentation process period varied from 6 to 34 hours and curd concentration was from 6.6 to $16.4 \%$. The standard methodology was followed for the analysis of all the parameters studied. The product varied formulations had quinine range of 119 to $327.5 \mathrm{mg} \%$, antioxidants $40.2-64.5 \%$, total phenols 30.5 to $42.5 \mathrm{mg} \%$, water soluble vitamins; $\mathrm{B}_{1}-0.07$ to $0.81 \mathrm{mg} \%, \mathrm{~B}_{2}-0.02$ to $0.28 \mathrm{mg} \%, \mathrm{~B}_{3}-0.4$ to $1.08 \mathrm{mg} \%, \mathrm{~B}_{6}-0.04$ to $0.32 \mathrm{mg} \%$ and vitamin-C -17.2 to $34.6 \mathrm{mg} \%$. Fermentation time for 30 hours and curd concentration of $15 \%$ was the optimized composition with the best fit of desirability 0.80 . The product with the good taste and flavour was acceptable with 6.7 score on 9-pont hedonic scale. The fermented bittergourd beverage was preferred to fresh bittergourd juice.
\end{abstract}

Keywords: Bittergourd, Curd, Fermentation, RSM, Quinine, Vitamins.

\section{INTRODUCTION}

Vegetables are strongly recommended in the human diet since they are rich in antioxidants, vitamins, dietary fibres and minerals. The major part of the vegetables consumed in the human diet are fresh, minimally processed, pasteurized or cooked by boiling in water or microwaving. Minimally processed and especially, fresh vegetables have a very short shelf life since subjected to rapid microbial spoilage and the above cooking processes would bring about a number of not always desirable changes in physical characteristics and chemical composition of vegetables $[1,2]$. Among the various technological options, lactic acid fermentation may be considered as a simple and valuable biotechnology for maintaining and/or improving the safety, nutritional, sensory and shelf life properties of vegetables [3, 4]. Lactic acid fermentation of vegetables has nowadays an industrial significance only for cucumbers, cabbages, red beet, carrot, celery, tomato and olives $[5,6]$. However, the studies on nutrient profile have not received much attention. Momordica charantia $L$ also known as bittermelon, bittergourd, balsam pear or karela is widely cultivated as a vegetable and medicinal herb in many Asian countries and has been shown to exert hypoglycemic effects in animal models and humans. Bittergourd fruit can be preserved by dehydration, steeping

*Address corresponding to this author at the Food Preservation Discipline, Defence Food Research Laboratory, Siddarthanagar, Mysore - 570 011, Karnataka, India; Tel: 0821 - 2473828; Fax: 0821 - 2473468;

E-mail: dfrimysore@sancharnet.in preservation and pickling but no work has been done to prepare fermented beverage from bittergourd in India. Studies on the use of lactic acid bacteria starters to get reliable and controlled fermentation processes should be warranted [7]. Although a large number of lactic acid bacteria starters are routinely used in dairy, meat and baked good fermentations, only a few cultures have been used for vegetable fermentations. Keeping this in view an attempt is made to develop nutritionally strengthful, highly acceptable, shelf stable bittergourd fermented beverage using natural mixed culture of curd by using statistical software by RSM for persons suffering from diabetes. The optimization of the fermentation process with reference to curd concentration and the period has been attempted by using RSM with more emphasis on nutritional and functional considerations. However, the studies on nutrient profile has not received much attention thus the fermentation conditions followed for vegetable juices and the changes in their nutrients still needs a radical approach to achieve the best quality product. Therefore in the present study, the raw material bittergourd, statistical design using RSM, an effective tool for optimization have been used with an attempt to bring out the nutritional strength of the fermentation process.

\section{MATERIALS AND METHODS}

\subsection{Materials}

Good quality raw materials i.e. bittergourd (Momordica charantia) - light green variety, salt, lemon 
were procured from local market and milk, curd were procured from Nandini milk parlour, Mysore. All the chemical and reagents used for the analysis were AR grade. For HPLC analyses HPLC grade solvents and standards were procured from $\mathrm{M} / \mathrm{s}$ SK Chemicals, Burdick and Jackson, HPLC certified solvents and M/s Sigma Aldrich, St.Louis, USA.

\subsection{Raw Material Processing}

Bittergourd were sorted, washed thoroughly in running water to remove adhering foreign materials and cut horizontally, removed seeds, cleaned in salt water and cut into pieces, blanched at $90^{\circ} \mathrm{C}$ for 5 mins with $0.1 \%$ Potassium metabisulphite and $0.05 \%$ Magnesium oxide and extracted the juice using a juice extractor (RayLons Metal Works, Bombay, India). Curd was added $(6.6$ to $16.4 \mathrm{gm} / 100 \mathrm{ml})$ and fermented at room temperature for 6 to 34 hours period by adding $2 \%$ salt. Good quality milk was seeded with curd (2\%) and kept at $37^{\circ} \mathrm{C}$ for 10 hours and was homogenized and used for fermentation.

\subsection{Experimental Design}

The percentage of curd concentration and time of fermentation was as per the runs obtained by design expert statistical software. A Central Composite Rotatable Design was used without blocking. The number of design points were obtained on basis of the number of independent variables decided. The statistical software package design expert 8.0.2, Stat Ease Inc., Minneapolis, MN, was used to construct the experimental design as well as analyze the data. The parameters that influence the product quality, acceptability and functionality were taken as responses. Variables curd concentration and fermentation period were selected as independent variables and quinine $(\mathrm{mg} \%)$, total phenols $(\mathrm{mg} \%)$, antioxidants (\%), Water soluble vitamins (mg\%)- $B_{1}, B_{2}$, $B_{3}, B_{6}$ and vitamin-C were selected as the responses. The factorial design considered 4 factorial points, 4 axial points and 5 central points leading to 13 sets of experiments [8]. Optimized ranges of the variables are shown in Table 1. Each independent variable investigated in this experiment had five levels which were $-1.4142,-1,0,+1$ and +1.4142 . A total of 13 level combinations (design points) were generated for the two independent variables and the alpha values in the design outside the ranges were selected for rotatability of the design. The center point (the level combination in which the value of each coded variable was 0 ) was repeated five times for the two-variable design and was selected keeping the ingredients at levels expected to yield, at least, satisfactory experimental results.

The regression analysis of the responses was conducted by fitting to the suitable model represented by the following equation

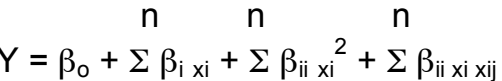

$$
\begin{aligned}
& i=1 \quad i=1 \quad i \neq j=1
\end{aligned}
$$

where, $\beta_{0}$ was the value of the fitted response at the center point of the design, while $\beta_{i}, \beta_{i i}$, and $\beta_{i j}$ were the linear, quadratic and interactive-effect regression terms, respectively, and $n$ denoted the number of independent variables i.e. in this case $n$ is 2 , and $x_{i}, x_{i j}$ are independent variables in coded values represented by $X_{1}$ and $X_{2}$ in Table 2 .

After fermentation for varied periods the respective samples were filtered in muslin cloth. Then the bottles were sealed and pasteurized for $15 \mathrm{mins}$ at $90^{\circ} \mathrm{C}$. The samples were analysed immediately after the completion of the fermentation process.

Table 1: Process Variables Their Levels and Experimental Design

\begin{tabular}{|c|c|c|c|c|c|}
\hline Process variables & $\begin{array}{c}-1.414 \\
\text { (augmented form) }\end{array}$ & $\begin{array}{c}-1 \\
\text { (factorial point) }\end{array}$ & $\begin{array}{c}0 \\
\text { (centre point) }\end{array}$ & $\begin{array}{c}+1 \\
\text { (factorial point) }\end{array}$ & $\begin{array}{c}+1.414 \\
\text { (augmented form) }\end{array}$ \\
\hline Fermentation (Hours) & 6 & 10 & 20 & 30 & 34 \\
\hline Curd (gm/100ml) & 6.6 & 8 & 11.5 & 15 & 16.4 \\
\hline
\end{tabular}

\begin{tabular}{|c|c|c|}
\hline $\mathbf{X}_{\mathbf{1}}$ & $\mathbf{X}_{\mathbf{2}}$ & Runs \\
\hline \hline \pm 1 & \pm 1 & 4 \\
\hline \pm 1.414 & 0 & 2 \\
\hline 0 & \pm 1.414 & 2 \\
\hline 0 & 0 & 5 \\
\hline
\end{tabular}


Table 2: Actual Experimental Combinations and Response Values

\begin{tabular}{|c|c|c|c|c|c|c|c|c|c|c|}
\hline Exp. No & $X_{1}$ & $X_{2}$ & $\begin{array}{c}\text { Response } \\
1\end{array}$ & $\begin{array}{c}\text { Response } \\
2\end{array}$ & $\begin{array}{c}\text { Response } \\
3\end{array}$ & $\begin{array}{c}\text { Response } \\
4\end{array}$ & $\begin{array}{c}\text { Response } \\
5\end{array}$ & $\begin{array}{c}\text { Response } \\
6\end{array}$ & $\begin{array}{c}\text { Response } \\
7\end{array}$ & $\begin{array}{c}\text { Response } \\
8\end{array}$ \\
\hline \multirow[t]{3}{*}{ Run } & A:Time & B:Curd & Quinine & Antioxidants & $\begin{array}{c}\text { Total } \\
\text { Phenols }\end{array}$ & Thiamine & Riboflavin & Niacin & Pyridoxine & Vitamin C \\
\hline & Hours & $\%$ & $\mathrm{mg} \%$ & $\%$ & $\mathrm{mg} \%$ & $\mathrm{mg} \%$ & $\mathrm{mg} \%$ & $\mathrm{mg} \%$ & $\mathrm{mg} \%$ & $\mathrm{mg} \%$ \\
\hline & & & $Y_{1}$ & $Y_{2}$ & $Y_{3}$ & $Y_{4}$ & $Y_{5}$ & $Y_{6}$ & $Y_{7}$ & $Y_{8}$ \\
\hline 1 & 10 & 8.0 & 299.9 & 42.5 & 36.6 & 0.81 & 0.019 & 0.67 & 0.092 & 17.2 \\
\hline 2 & 30 & 8.0 & 245.3 & 51 & 39.1 & 0.33 & 0.098 & 0.76 & 0.3 & 27.6 \\
\hline 3 & 10 & 15.0 & 158.6 & 64.5 & 42.5 & 0.11 & 0.2 & 0.86 & 0.081 & 21.7 \\
\hline 4 & 30 & 15.0 & 286 & 54.1 & 41.2 & 0.32 & 0.28 & 0.7 & 0.27 & 33.4 \\
\hline 5 & 6 & 11.5 & 172.5 & 56.5 & 41.35 & 0.6 & 0.075 & 1.08 & 0.042 & 18 \\
\hline 6 & 34 & 11.5 & 237.1 & 55 & 38.5 & 0.4 & 0.22 & 1.02 & 0.32 & 34.6 \\
\hline 7 & 20 & 6.6 & 327.5 & 40.2 & 36.35 & 0.5 & 0.035 & 0.4 & 0.2 & 20.5 \\
\hline 8 & 20 & 16.4 & 253.5 & 59.3 & 39.8 & 0.068 & 0.24 & 0.4 & 0.17 & 27.2 \\
\hline 9 & 20 & 11.5 & 132.3 & 54.2 & 30.5 & 0.4 & 0.19 & 0.86 & 0.15 & 24.9 \\
\hline 10 & 20 & 11.5 & 119 & 55.2 & 34.63 & 0.35 & 0.19 & 0.89 & 0.16 & 26 \\
\hline 11 & 20 & 11.5 & 127.7 & 54.5 & 34.05 & 0.4 & 0.24 & 0.8 & 0.15 & 25.1 \\
\hline 12 & 20 & 11.5 & 128.9 & 52.6 & 34.5 & 0.4 & 0.25 & 0.9 & 0.16 & 25 \\
\hline 13 & 20 & 11.5 & 134 & 53.9 & 35.6 & 0.35 & 0.24 & 0.9 & 0.149 & 25.8 \\
\hline
\end{tabular}

\subsection{Analytical Evaluation}

The fermented bittergourd juice was analysed for quinine [9], total phenols and free radical scavenging capacity (DPPH activity) [10], and water soluble vitamins i.e., thiamine, riboflavin, niacin, pyridoxine and vitamin $\mathrm{C}$ analysis were performed using HPLC on reverse phase $C_{18}$ analytical column [11].

The analysis for all the parameters was carried out in duplicate and the average value has been reported.

\subsection{Organoleptic Evaluation}

A semi trained panel evaluated the samples for bitterness, colour, aroma, taste and overall acceptability using a nine point hedonic scale [12]. The samples were subjected to microbiological analysis for the study of TPC, Coli, Yeast and Moulds. Fresh bittergourd juice, fresh bittergourd beverage with dilution and optimised fermented bittergourd beverage and fermented diluted beverage were served to the panel members at room temperature. Samples were randomly drawn for each experimental block, coded and served to the panelists.

\section{RESULTS AND DISCUSSIONS}

The experimental central composite rotatable design with independent variables and responses is given in Table 2. Over the 13 combinations quinine ranged from 119 to $327.5 \mathrm{mg} \%$, antioxidants 40.2 to $64.5 \%$, total phenols 30.5 to $42.5 \mathrm{mg} \%$, water soluble vitamins; $B_{1}-0.07$ to $0.81 \mathrm{mg} \%, B_{2}-0.02$ to 0.28 $\mathrm{mg} \%, \mathrm{~B}_{3}-0.4$ to $1.08 \mathrm{mg} \%, \mathrm{~B}_{6}-0.04$ to $0.32 \mathrm{mg} \%$ and vitamin $-\mathrm{C}-17.2$ to $34.6 \mathrm{mg} \%$.

The effects of the independent variables curds and fermentation time on the response at linear, quadratic and interactive levels are presented in Table 3 . The sign and magnitude of the coefficients indicate the effect of the variable on the responses. Negative sign of a coefficient at linear level indicates decrease in response with an increase in level of the variable where as at interactive level, level of one variable could be increased while that of the other decreased to obtain the same response.

All main, linear, quadratic and interactive effects were calculated for each model. Quadratic response surface models were selected for all the responses. The adequacy was calculated by F-ratio, mean, standard deviation, coefficient correlation and lack of fit test. $\mathrm{R}^{2}$ value was more than $90 \%$ and lack of fit was highly non-significant. The regression coefficient, correlation coefficient for the responses were 0.99 for quinine, antioxidant activity, $B_{1}, B_{6}$, Vitamin $C$ and 0.98 for $B_{3}, 0.95$ for $B_{2}$ respectively indicating that all the values were more than $90 \%$. The $\mathrm{R}^{2}$ value for total phenols was 0.85 , but because of the subjective nature 
Table 3: Coefficient of Second Order Polynomial Regression Models

\begin{tabular}{|c|c|c|c|c|c|c|c|c|}
\hline Coefficient & Quinine & Antioxidants & $\begin{array}{c}\text { Total } \\
\text { Phenols }\end{array}$ & Thiamine & Riboflavin & Niacin & Pyridoxine & Vitamin-C \\
\hline & $\mathrm{mg} \%$ & $\mathrm{mg} \%$ & $\%$ & $\mathrm{mg} \%$ & $\mathrm{mg} \%$ & $\mathrm{mg} \%$ & $\mathrm{mg} \%$ & $\mathrm{mg} \%$ \\
\hline & $Y_{1}$ & $Y_{2}$ & $Y_{3}$ & $\mathrm{Y}_{4}$ & $Y_{5}$ & $Y_{6}$ & $Y_{7}$ & $Y_{8}$ \\
\hline$\beta_{0}$ & 128.38 & 54.08 & 33.87 & 0.38 & 0.22 & 0.87 & 0.154 & 25.36 \\
\hline$\beta_{1}$ & $20.51^{* \star \star *}$ & -0.502 & -0.354 & $-0.069^{\star \star \star *}$ & $0.0455^{\star *}$ & -0.019 & $0.099^{\star \star \star *}$ & $5.69^{\star \star \star *}$ \\
\hline$\beta_{2}$ & $-25.65^{\star * * *}$ & $6.51^{* * * *}$ & $1.609^{*}$ & $-0.165^{\star * * *}$ & $0.0816^{* * * *}$ & 0.0163 & $-0.010^{* * *}$ & $2.47^{* * * *}$ \\
\hline$\beta_{11}$ & $38.16^{\star \star \star *}$ & 0.904 & $3.247^{* *}$ & $0.06^{* * *}$ & $-0.035^{\star *}$ & $0.096^{* * *}$ & $0.014^{\star * * *}$ & $0.445^{\star}$ \\
\hline$\beta_{22}$ & $81.01^{* * * *}$ & $-2.096^{* * *}$ & $3.23^{* *}$ & $-0.0478^{* *}$ & $-0.040^{* *}$ & $-0.229^{* * * *}$ & $0.016^{* * * *}$ & $-0.78^{* *}$ \\
\hline$\beta_{12}$ & $45.5^{\star * \star *}$ & $-4.725^{\star * * *}$ & -0.95 & $0.1725^{\star * \star *}$ & 0.00025 & $-0.0625^{\star}$ & -0.0048 & 0.325 \\
\hline $\mathrm{R}^{2} \%$ & 99.74 & 99.09 & 85.27 & 99.00 & 95.11 & 97.96 & 99.82 & 99.57 \\
\hline $\mathrm{p} \%$ & $<0.0001$ & $<0.0001$ & $<0.01$ & $<0.0001$ & $<0.001$ & $<0.0001$ & $<0.0001$ & $<0.0001$ \\
\hline Mean & 201.72 & 53.34 & 37.28 & 0.387 & 0.175 & 0.788 & 0.173 & 25.15 \\
\hline SD & 5.08 & 0.782 & 1.75 & 0.024 & 0.025 & 0.038 & 0.0046 & 0.43 \\
\hline F-value & 526.06 & 154.03 & 8.11 & 139.27 & 27.28 & 67.38 & 785.13 & 326.08 \\
\hline
\end{tabular}

Note: Significance: ${ }^{* * *} p>0.0001,{ }^{* * *} p<0.001,{ }^{* *} p<0.01,{ }^{*} p<0.05$.

of the response the model is considered significant (Table 3).

\subsection{Effect of Variables on Functional Parameters}

Quinine, total phenols and antioxidant activity were considered as functional parameters for the independent variables. Phenolics or polyphenols have received considerable attention because of their physiological function, including antioxidant, antimutagenic and antitumour activities [13]. Plant phenolics present in fruit and vegetables have received considerable attention because of their potential antioxidant activity [14]. Phenolic compounds are widely distributed in plants [15], which have gained much attention due to their antioxidant activities and free radical scavenging abilities, which potentially have beneficial implications for human health $[15,16]$. Total phenol content was determined in comparison with standard Gallic acid and the results are expressed in $\mathrm{mg} / 100 \mathrm{ml}$ of sample. $\mathrm{Wu}$ and $\mathrm{Ng}$ [17] found that extracts of wild bittermelon, possessed potent antioxidant and free radical scavenging activities. Some researchers have also found that Thai bittergourd fruit contained anticarcinogens or chemopreventive agent [18, 19]. However no report exists on fermentation effect on total phenols and antioxidant activity on bittergourd. Table 3 reveals that at linear level time had a significant $(p<0.0001)$ positive effect on quinine content, while it had a negative effect on total phenols and antioxidant activity. Curd had a significant $(p<0.0001)$ negative effect on quinine content where as it had a significant $(p<0.0001$ \& $p<0.05)$ positive effect on antioxidant activity and total phenol content respectively at linear levels. At quadratic level both fermentation time and curd concentration had a positive highly significant level at $p<0.0001$ for quinine and $p<0.001$ on total phenols, while antioxidant activity was negatively affected by curd at $p<0.001$. Fermentation time and curd had positive significant $(p<0.0001)$ effect $(p<0.01)$ on quinine level and variables showed negative significant $(p<0.0001)$ effect on antioxidant activity at interactive level. The multiple coded equations in terms of coded factors generated for their responses are shown below:

Quinine $=$

$$
\begin{aligned}
& 128.38+20.519 X_{1}-25.656 X_{2} \\
& +38.16 X_{1}^{2}+81.01 X_{2}^{2} \\
& +45.5 X_{1} X_{2} \quad R^{2}=0.99
\end{aligned}
$$

Antioxidants $=54.08-0.502 X_{1}+6.514 X_{2}$

$$
\begin{array}{ll}
+0.903 X_{1}^{2}-2.096 X_{2}^{2} & \\
-4.725 X_{1} X_{2} & R^{2}=0.99
\end{array}
$$

Total Phenols $=33.85-0.358 \mathrm{X}_{1}+1.609 \mathrm{X}_{2}$

$$
\begin{array}{ll}
+3.247 X_{1}^{2}+2.322 X_{2}^{2} & \\
-0.95 X_{1} X_{2} & R^{2}=0.85
\end{array}
$$

The response surface for quinine, total phenols and antioxidants in relation to fermentation time and curd is 

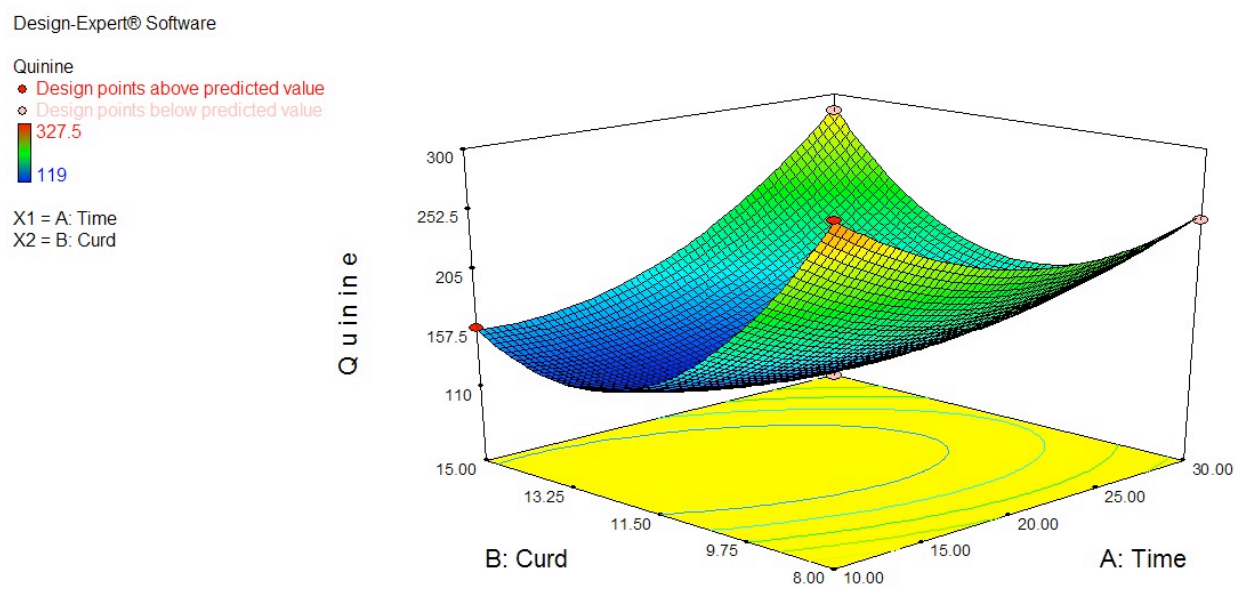

a
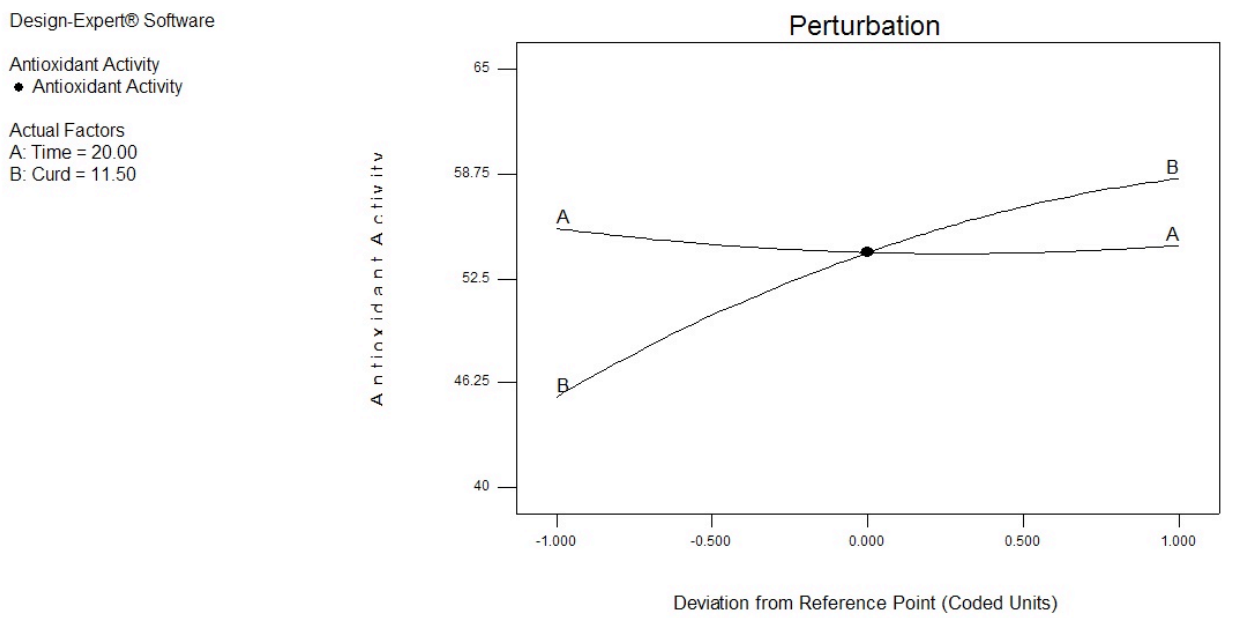

b
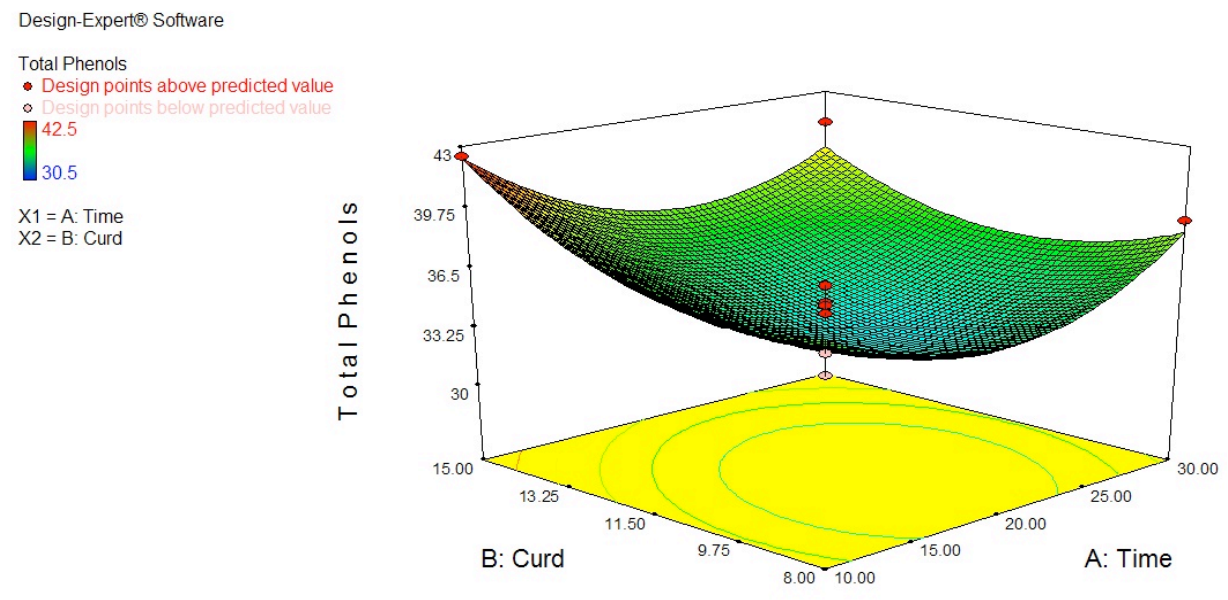

C

Figure 1: Perturbation graphs depicting effect of independent variables on functional parameters of the fermented beverage.

shown in Figure (1a, $\mathbf{1 b}$ and $\mathbf{1 c})$ respectively. As curd concentration increased total phenols and antioxidants increased and as fermentation decreased there was increase in total phenol level of beverage. Kubola et al. [10] reported that bittergourd fractions are rich in phenolics and have a strong antioxidant activity and a radical-scavenging action.

\subsection{Effect of Variables on Nutritional Parameters}

Since the time fermented products have had an image of possessing almost magical health-giving properties. However, the knowledge of how lactic acid fermentation influences the nutritional value of products is poor and many of the nutritional aspects of 
fermented products still have to be subjected to in depth scientific investigations. Thus the effect of fermentation time and starter culture concentration on water soluble vitamins formation was studied in the current study. The model obtained from the regression can be written as follows for nutritional parameters.

$$
\begin{aligned}
& \text { Thiamine }=\quad 0.38-0.069 \mathrm{X}_{1}-0.165 \mathrm{X}_{2} \\
& +0.060 x_{1}^{2}-0.0478 x_{2}^{2} \\
& +0.173 X_{1} X_{2} \quad R^{2}=0.99 \\
& \text { Riboflavin }=\quad 0.222+0.0455 X_{1}+8.6925 X_{2} \\
& -0.035 X_{1}^{2}-0.040 X_{2}^{2} \\
& +0.00025 X_{1} X_{2} \quad R^{2}=0.95 \\
& \text { Niacin }=\quad 0.87-0.019 X_{1}+0.016 X_{2} \\
& +0.0956 X_{1}^{2}-0.229 X_{2}^{2} \\
& \begin{array}{ll}
-0.0625 X_{1} X_{2} & R^{2}=0.98
\end{array} \\
& +33.7317 X_{1}^{2}-6.3412 X_{2}^{2} \\
& \begin{array}{ll}
-22.53 X_{1} X_{2} & R^{2}=0.99
\end{array} \\
& +0.445 X_{1}^{2}-0.78 X_{2}^{2} \\
& +0.325 X_{1} X_{2} \quad R^{2}=0.99
\end{aligned}
$$

From the above equation, it can be concluded that thiamine had significant $(p<0.0001)$ negative effect on linear model. Curd concentration had a highly significant $(p<0.0001)$ positive effect on riboflavin and vitamin- $C$ where as it affected pyridoxine levels negatively at $p<0.001$ and niacin was insignificant at linear level. At linear level fermentation time had a highly significant $(p<0.0001)$ positive effect on pyridoxine and vitamin $\mathrm{C}$, while riboflavin had significant $(p<0.01)$ positive effect and niacin was insignificant. Fermentation time had negative effect on riboflavin at quadratic level with the significance level of $p<0.01$ and curd concentration had negative effect on thiamine, riboflavin, vitamin $C$ with significance level of $p<0.01$, niacin with significance level of $p<0.0001$ while it was positively significant $(p<0.0001)$ for pyridoxine at quadratic level. Fermentation time affected pyridoxine at significance level of $p<0.0001$, thiamine and niacin at $p<0.001$ and vitamin $C$ at $p<0.01$ at quadratic level while it affected negatively on riboflavin $(p<0.001)$. At interactive level, fermentation time and curd concentration affected the thiamine significantly at $p<0.0001$, niacin at $p<0.01$ while variables had no significant effect on riboflavin, pyridoxine and Vitamin $\mathrm{C}$ retention. It is clear from Figure (2a to $2 \mathbf{e})$, as there was increase in fermentation time there was increase in riboflavin, pyridoxine and vitamin $\mathrm{C}$ content and with increase in curd concentration, there was increase in riboflavin and vitamin C content. Thus the graph explains that fermentation time and curd concentration has great influence on vitamin profile.

\subsection{Optimization of Independent Variables}

Numerical optimization of independent variables, fermentation time and curd concentration were optimized using Design Expert Software. The criteria used along with the predicted and actual values of the response are given in Table 4. The aim of the experiment was to maximize the formation of water soluble vitamins and increase the antioxidant activity. The solution which was obtained was 30 hours of fermentation time and $15 \%$ of curd with best fit desirability of 0.80 . The optimized results were quinine $287.9 \mathrm{mg} \%$, antioxidants $54.2 \%$, total phenols 39.7 $\mathrm{mg} \%$, vitamin $\mathrm{B}_{1} 0.33 \mathrm{mg} \%, \mathrm{~B}_{2} 0.27 \mathrm{mg} \%, \mathrm{~B}_{3} 0.67 \mathrm{mg} \%$, $\mathrm{B}_{6} 0.27 \mathrm{mg} \%$ and vitamin-C $33.5 \mathrm{mg} \%$. The predicted response value as against actual value for responses as shown in Table 4 were in concurrence with each other, hence the similar fitted models are suitable for predicting the responses.

When compared with the bittergourd juice, optimized fermented bittergourd beverage was higher in antioxidant levels, total phenols content, thiamine, riboflavin and vitamin C content (Table 5). Sensory scores of bittergourd juice, bittergourd diluted beverage, bittergourd fermented beverage and bittergourd diluted fermented beverage is presented in Table 6. The bittergourd juice and fermented bittergourd beverage were analysed for microbiological status and the results revealed that the products were free from TPC, coli and yeast and moulds and were fit to drink. The safe product was subjected to sensory analysis and product bittergourd fermented beverage with the good taste and flavour was acceptable with 6.7 score on 9-pont hedonic scale in diabetic panelists and 6.2 score in non diabetic panelists. The sensory quality of the fermented bittergourd beverage was scored above acceptable range when compared with fresh bittergourd juice and the preferred quantity of fermented beverage consumption was higher than the fresh bittergourd juice. 
Design-Expert $\circledast$ Software

Thiamine

- Thiamine

Actual Factors

A: Time $=20.00$

B: Curd $=11.50$

Design-Expert® Software

Riboflavin

- Design points above predicted value

- Design points above predicted value

0.28

0.019

$\mathrm{X} 1=\mathrm{A}:$ Time X2 = B: Curd

$\frac{1}{7}$
$\frac{\pi}{4}$
0
$\frac{0}{\alpha}$
$\frac{1}{\alpha}$

Design-Expert@ Software

Niacin

- Niacin

Actual Factors

A: Time $=20.00$
B: Curd $=11.50$

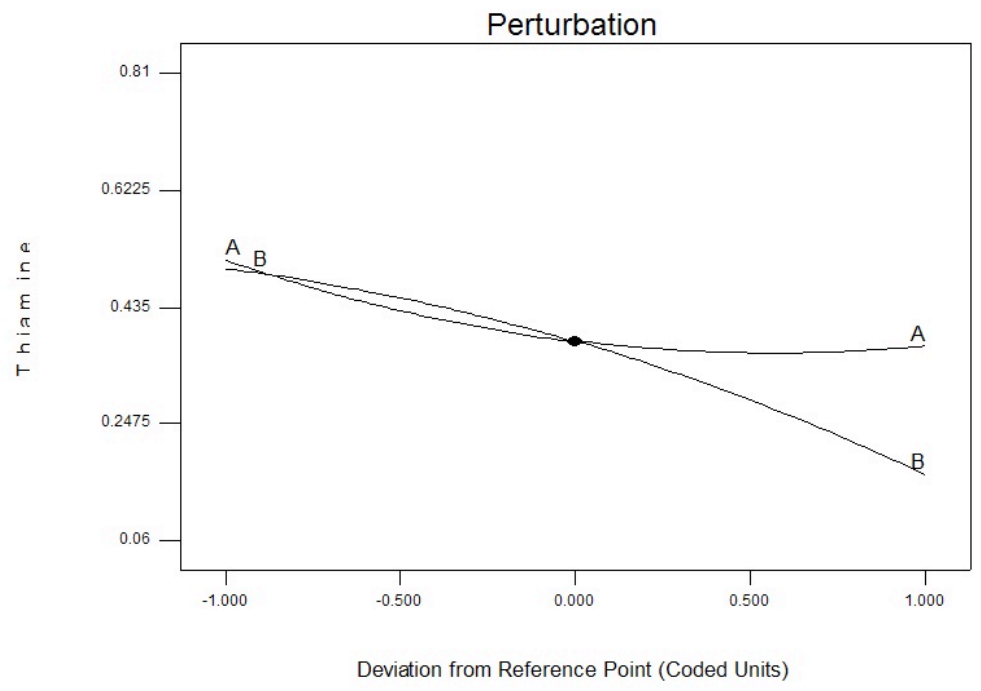

a

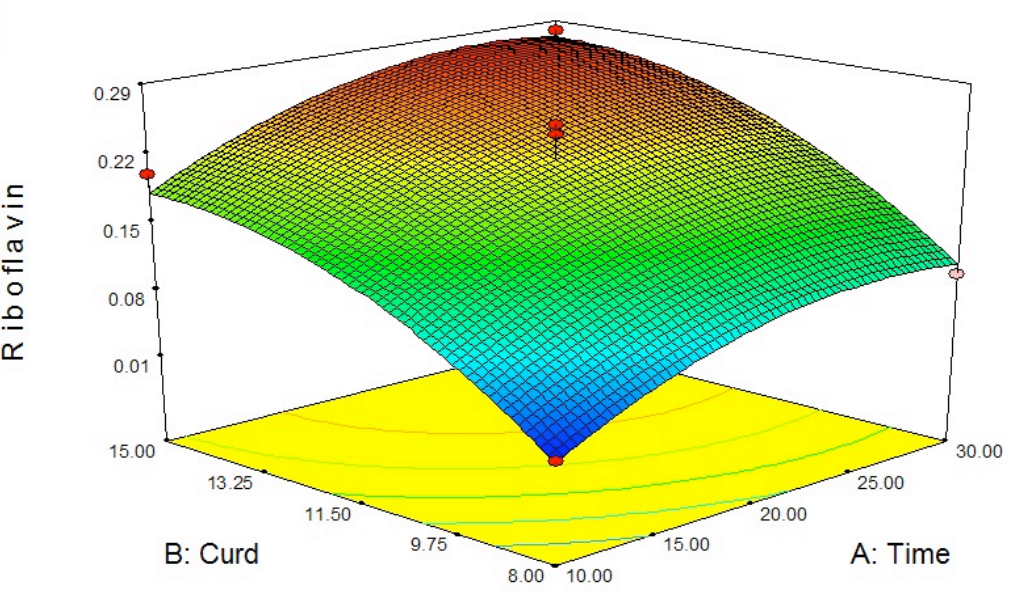

b

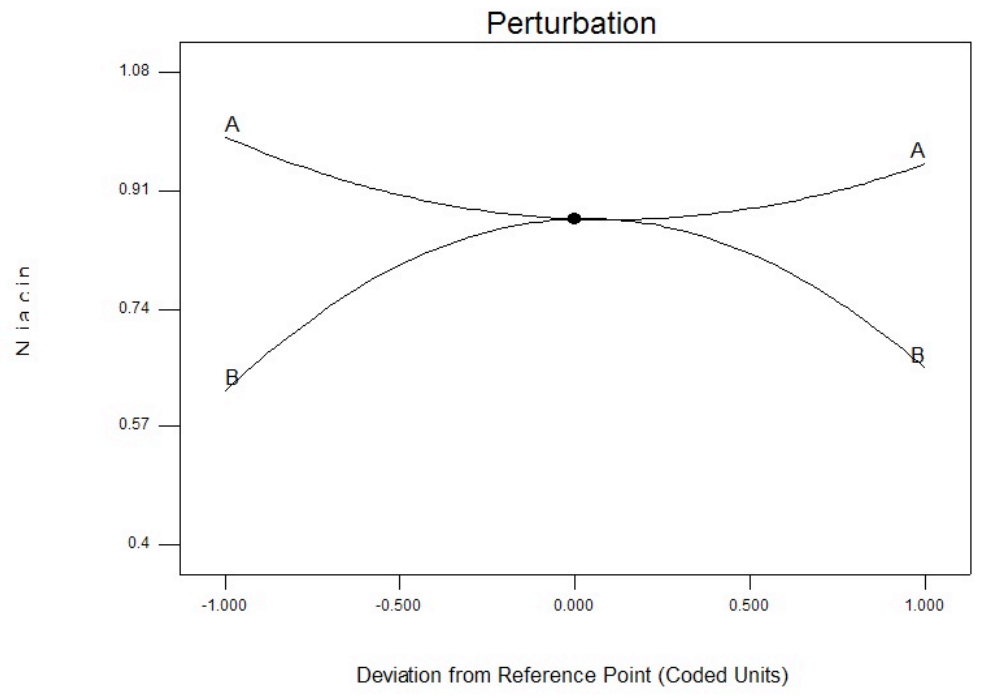

C 
Design-Expertæ Software

Pyridoxine

- Pyridoxine

Actual Factors

A: Time $=20.00$

B: Curd $=11.50$

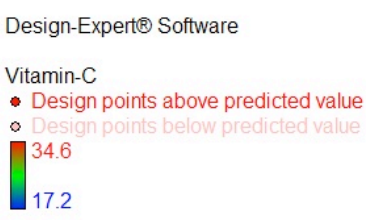

$\mathrm{X} 1=\mathrm{A}:$ Time $\mathrm{X} 2=\mathrm{B}:$ Curd

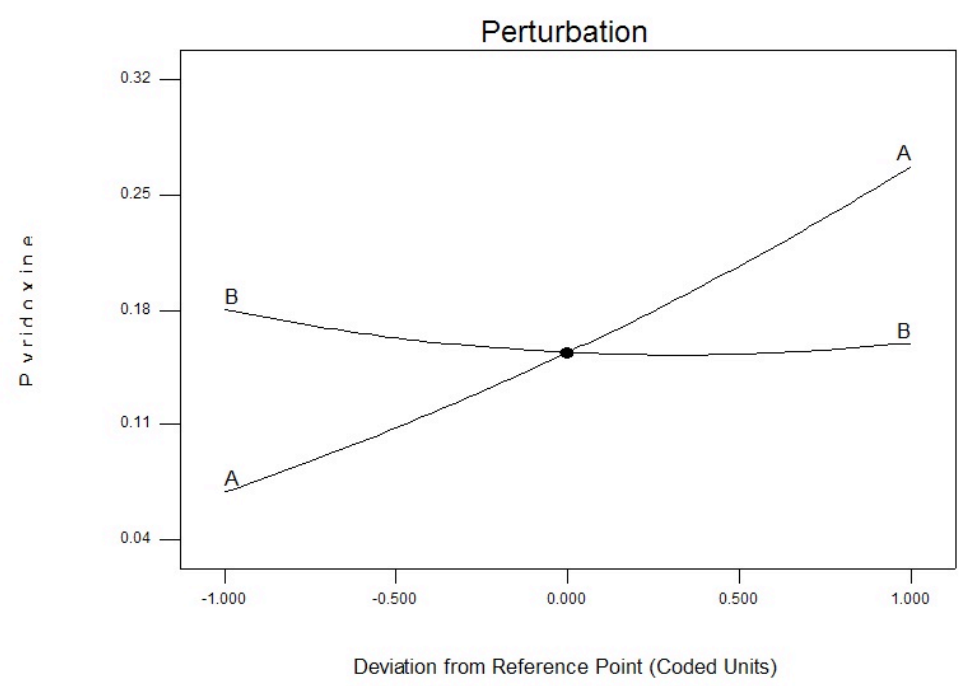

d

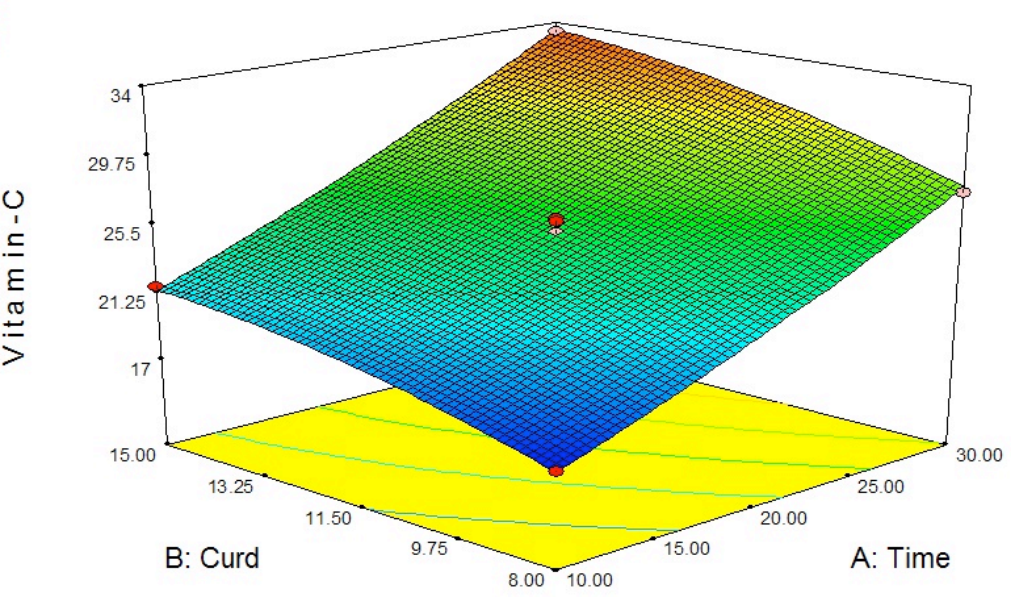

Figure 2: Perturbation graph and 3D plots depicting effect of independent variables on Nutritional Parameters of the fermented beverage.

Table 4: Predicted and Actual Response Values

\begin{tabular}{|c|c|c|}
\hline Responses & Actual & Prediction \\
\hline Quinine (mg\%) & 287.9 & 297.4 \\
\hline Antioxidants (\%) & 54.2 & 55.6 \\
\hline Total Phenols (mg\%) & 39.7 & 43.0 \\
\hline Thiamine (mg\%) & 0.33 & 0.38 \\
\hline Riboflavin (mg\%) & 0.27 & 0.32 \\
\hline Niacin (mg\%) & 0.67 & 0.74 \\
\hline Pyridoxine (mg\%) & 0.27 & 0.28 \\
\hline Vitamin C (mg\%) & 33.5 & 34.3 \\
\hline
\end{tabular}


Table 5: Functional and Nutritional Parameter of Bittergourd Juice and Bittergourd fermented beverage

\begin{tabular}{|c|c|c|}
\hline Parameters & Fresh Juice & 287.9 \\
\hline \hline Quinine (mg \%) & 426 & 54.2 \\
\hline Antioxidants (\%) & 44 & 39.7 \\
\hline Total Phenols (mg \%) & 20 & 0.33 \\
\hline Thiamine (mg \%) & 0.16 & 0.27 \\
\hline Riboflavin (mg \%) & 0.15 & 0.67 \\
\hline Niacin $(\mathrm{mg} \%)$ & 0.7 & 0.27 \\
\hline Pyridoxine $(\mathrm{mg} \%)$ & 0.3 & 33.5 \\
\hline Vitamin C (mg \%) & 28 & \\
\hline
\end{tabular}

Table 6: Sensory Score of Bittergourd Juice and Fermented Beverage, $n=10$

\begin{tabular}{|c|c|c|c|c|c|c|c|}
\hline Types & Subjects & Bitterness & Color & Aroma & Taste & OAA* $^{*}$ & $\begin{array}{l}\text { Preferred } \\
\text { quantity to } \\
\text { drink }\end{array}$ \\
\hline \multirow[t]{2}{*}{ Bittergourd Juice } & Non - Diabetic & $6.4 \pm 1.4$ & $6.8 \pm 0.8$ & $5.1 \pm 2.6$ & $5.4 \pm 1.8$ & $5.2 \pm 1.4$ & $34 \pm 32$ \\
\hline & Diabetic & $6.5 \pm 1.6$ & $6.5 \pm 0.8$ & $5.5 \pm 0.8$ & $5.5 \pm 0.8$ & $4.5 \pm 0.8$ & $45 \pm 12$ \\
\hline $\begin{array}{l}\text { Bittergourd Beverage } \\
\text { (Diluted) }\end{array}$ & Non - Diabetic & $6.2 \pm 1.5$ & $6.6 \pm 1.5$ & $5.8 \pm 2.4$ & $6.2 \pm 1.2$ & $6.0 \pm 1.4$ & $36 \pm 31$ \\
\hline $\begin{array}{c}\text { Bittergourd Fermented } \\
\text { Beverage }\end{array}$ & Diabetic & $5.3 \pm 0.8$ & $6.5 \pm 0.8$ & $5.8 \pm 0.8$ & $6.3 \pm 1.6$ & $6.7 \pm 2.1$ & $75 \pm 27$ \\
\hline \multirow{2}{*}{$\begin{array}{l}\text { Bittergourd Fermented } \\
\text { Beverage (Diluted) }\end{array}$} & Non - Diabetic & $5.2 \pm 2.2$ & $6.6 \pm 0.8$ & $6.1 \pm 1.6$ & $6.3 \pm 1.8$ & $5.9 \pm 2.1$ & $38 \pm 31$ \\
\hline & Diabetic & $4.3 \pm 0.5$ & $6.5 \pm 0.8$ & $6 \pm 1.3$ & $6.1 \pm 1.3$ & $5.8 \pm 1.6$ & $58 \pm 20$ \\
\hline
\end{tabular}

Note: * Overall acceptability.

\section{CONCLUSION}

The application of RSM for optimizing the ingredients and process showed that quadratic response surface models were fitted. $F$ values were significant in all selected responses and a high $R^{2}$ value of $>90 \%$ showed fitness of the polynomial regression models for describing the effect of variables. The results of the study indicated that the effect of fermentation time and curd concentration were significant to all the selected responses and RSM could be useful in optimizing the curd concentration and fermentation time with maximum retention of vitamins. Using the optimized condition the prepared beverage from fermentation process contained more total phenolics, antioxidants, Vitamin $B_{1}, B_{2}, B_{3}, B_{6}$ and Vitamin $C$ when compared with fresh bittergourd juice. Overall the fermentation time and curd concentration is optimized with maximum retention of vitamins, antioxidants and total phenols with 30 hours of fermentation time and $15 \%$ curd concentration. The product with the good taste and flavour was acceptable with 6.7 score on 9-pont hedonic scale in diabetic panelists and 6.2 score in non diabetic panelists. The sensory quality of the fermented bittergourd beverage was scored above acceptable range when compared with fresh bittergourd juice and the preferred quantity of fermented beverage consumption was higher than the fresh bittergourd juice. From the study, it can be concluded that the fermented bittergourd beverage was nutritionally and functionally strengthful and highly acceptable.

\section{ACKNOWLEDGEMENT}

The authors sincerely thank the Director Dr. A S Bawa, DFRL, Mysore for his support and encouragement.

\section{REFERENCES}

[1] Zia-ur-Rehman Z, Islam M, Shah WH. Effect of microwave and conventional cooking on insoluble dietary fibre components of vegetables. Food Chem 2003; $237-40$ http://dx.doi.org/10.1016/S0308-8146(02)00259-5

[2] Zhang D, Hamauzu Y. Phenolics, ascorbic acid, carotenoids and antioxidant activity of broccoli and their changes during conventional microwave cooking. Food Chem 2004; 88: 5039. http://dx.doi.org/10.1016/j.foodchem.2004.01.065 
[3] Buckenhuskes HJ, Holzapfel W. Genera Leuconostoc, Oenococcus and Weissella. Prokariotes 1997; 267-319.

[4] Steinkraus $\mathrm{KH}$. Indigenous fermented foods involving an acid fermentation: preserving and enhancing organoleptic and nutritional qualities if fresh foods. In: Steinkraus $\mathrm{KH}$, editor. Handbook of indigenous fermented food, $2^{\text {nd }}$ ed. New York: Marcel Dekker, Inc 1996; pp. 111-13.

[5] Karovicova Z, Kohajdova E, Hyenova. Chem Paper 2002; 56: $267-74$

[6] Montet D, Loiseau G, Zakhia-Rozis N. Microbial technology of fermented vegetables. In: Ray RC, Ward OP. editors. Micorbial biotechnology in horticulture. Science Publishers Inc, Enfield, NH 2006; pp. 303-43.

[7] McFeeters RF. Fermentation microorganisms and flavour changes in fermented food. J Food Sci 2004; 69: 35-37. http://dx.doi.org/10.1111/j.1365-2621.2004.tb17876.x

[8] Wadikar DD, Nanjappa C, Premavalli KS, Bawa AS. Development of ginger based ready-to-eat appetizers by response surface methodology. Appetite 2010; 55: 76-83. http://dx.doi.org/10.1016/j.appet.2010.04.004

[9] AOAC. Official methods of analysis. $12^{\text {th }}$ ed. Washington, DC: AOAC International 1975.

[10] Jittawan Kubola, Sirithon Siriamornpun. Phenolic contents and antioxidant activities of bittergourd (Momordica charantia $\mathrm{L})$ leaf, stem and fruit fraction exracts in vitro. Food Chem 2008; 110: 881-90. http://dx.doi.org/10.1016/i.foodchem.2008.02.076

[11] Ing H-Knauer. Rapid analysis of water-soluble vitamins using smartline HPLC. [cited 2010 Apr] Available from: http://www.knauer.net/dwnld fls/a e rapid analysis water s oluble_vitamins_hphp.pdf

[12] Majumdar TK, Vasudish CR. Premavalli KS, Bawa AS. Studies on processing and storage stability of ashgourd-mint leaves juice. J Food Proc Preser 2010; 34(Pt 2): 549-56.
[13] Othman A, Ismail A, Ghani NA, Adenan I. Antioxidant capacity and phenolic content of cocoa beans. Food Chem 2007; 100: 1523-30. http://dx.doi.org/10.1016/j.foodchem.2005.12.021

[14] Lopez-Velez M, Maritinez_Maritinez F, Del Valle-Ribes C. The study of phenolic compounds as natural antioxidants in wine. Crit Rev Fd Sci Nutr 2003; 43: 233-44.

[15] Li BB, Smith B, Hassain M. Extraction of phenolics from citrus peels I.solvent extraction method. Seperation Purification Technol 2006; 48: 182-88. http://dx.doi.org/10.1016/j.seppur.2005.07.005

[16] Govindarajan R, Singh DP, Rawat AKS. High performance liquid chromatographic method for the quantification of phenolics in chyavanprash a potent ayurvedic drug. J Pharm Biomed Anal 2007; 43: 527-32. http://dx.doi.org/10.1016/j.jpba.2006.08.005

[17] Wu SJ, Ng LT. Antioxidant and free radical scavenging activities of wild bittermelon (Momordica charantia Linn. var. abbereviata Ser) in Taiwan. LWT - Food Sci Technol 2007.

[18] Kusamran WR, Ratanavila A, Tepsuwan A. Effects of neem flowers, Thai and Chinese bitter gourd fruits and sweet basil leaves on hepatic monooxygenases and glutathione Stransferase activities, and in vitro metabolic activation of chemical carcinogens in rats. Fd Chem Toxicol 1998; 36: 475-84. http://dx.doi.org/10.1016/S0278-6915(98)00011-8

[19] Yasui Y, Hosokawa M, Sahara T, et al. Bitter gourd seed fatty acid rich in 9c,11t,13t-conjugated linolenic acid induces apoptosis and up-regulates the GADD45, p53 and PPAR? in human colon cancer Caco-2 cells. Prostaglandins Leukot Essent Fatty Acids 2005; 73(Pt 2): 113-9. http://dx.doi.org/10.1016/j.plefa.2005.04.013 